\title{
A novel Scanning Electrochemical Microscopy strategy for the investigation of anomalous hydrogen evolution from AZ63 magnesium alloy
}

\author{
D. Filotás ${ }^{1,2}$, B.M. Fernández-Pérez ${ }^{3}$, L. Nagy ${ }^{1,2}$, G. Nagy $^{1,2, *}$, R.M. Souto ${ }^{3,4, *}$ \\ ${ }^{1}$ Department for General and Physical Chemistry, Faculty of Sciences, University of Pécs, \\ Ifjúság útja 6, 7624 Pécs, Hungary. \\ 2 János Szentágothai Research Center, University of Pécs, Ifjúság u. 20, Pécs, 7624 Hungary. \\ ${ }^{3}$ Department of Chemistry, Universidad de La Laguna, Avda. Astrofísico Francisco Sánchez \\ s/n, E-38205 La Laguna (Tenerife), Canary Islands, Spain. \\ ${ }^{4}$ Institute of Material Science and Nanotechnology, Universidad de La Laguna, P.O. Box 456, \\ E-38200 La Laguna (Tenerife), Canary Islands, Spain.
}

\begin{abstract}
The evolution of hydrogen gas from corroding magnesium arises not exclusively from the cathodic half-cell reaction due to the consumption of the electrons released by the dissolving metal, but anodized magnesium generates significant amounts of $\mathrm{H}_{2}$ gas as well. In addition, the increase of the anodic overpotential enhances the rate of hydrogen gas generation. Therefore, spatially-resolved detection of the actual sites for hydrogen evolution related to anodically-activated sites is attempted using scanning electrochemical microscopy (SECM). This work describes a new experimental procedure for SECM based on a three-step (off-onoff) anodization operation sequence that was designed to obtain new insights into the behavior of magnesium and magnesium alloys when they are subjected to anodic polarization. Results obtained with scanning electrochemical microscopy (SECM) and scanning vibrating electrode technique (SVET) experiments presented here demonstrate the catalytic properties of the magnesium-oxide film for the hydrogen-evolution reaction.
\end{abstract}

Keywords: magnesium alloys; corrosion; hydrogen evolution; scanning electrochemical microscopy; scanning vibrating electrode technique. 


\section{Introduction}

Despite its outstanding mechanical properties, the extensive industrial use of magnesium remains limited due to its rapid degradation [1-3]. The characteristics of the spontaneous corrosion of magnesium are relatively well known. The dissolution of the metal occurs at the anodic sites according to Eq. (1), while the cathodic sites produce hydrogen gas and release hydroxide ions into the adjacent solution:

$$
\begin{aligned}
& \mathrm{Mg} \rightarrow \mathrm{Mg}^{2+}+2 \mathrm{e}^{-} \\
& 2 \mathrm{H}_{2} \mathrm{O}+2 \mathrm{e}^{-} \rightarrow \mathrm{H}_{2}+2 \mathrm{OH}^{-}
\end{aligned}
$$

However, the unusual evolution of hydrogen on the surface of magnesium under anodic polarization increasingly attracts attention $[4,5]$. Although it might be expected that the rate of magnesium dissolution should increase and the rate of the cathodic half-cell reaction should decrease as magnesium is biased towards more positive potentials from its open circuit potential (OCP), the evolution of hydrogen tends to be accelerated instead [6], a phenomenon traditionally called the negative difference effect (NDE), although it is effectively an anomalous hydrogen evolution process.

Until recently, the prevailing view was that the unipositive $\mathrm{Mg}^{+}$ion is formed at an early stage of metal dissolution, and this species reduces water to produce hydrogen gas and hydroxide ions [7,8]. To support this theory, the existence of unipositive $\mathrm{Mg}^{+}$has traditionally been invoked on the basis of an early work by Petty et al. [9], who reported the reduction of an oxidized species in the electrolyte separated from the dissolving magnesium anode which would require a strong reducing agent to be present in the solution. However, the lifetime of such hypothetical species remains unknown, and a recent replication of the experiment provided other explanations than the generation of unipositive $\mathrm{Mg}$ for the observed facts [10]. Therefore, several research groups have questioned the existence of that species [10-12]. An alternative mechanism for the enhanced cathodic activity on anodically polarized magnesium considers the metal impurities in the material [13]. However, the role of these impurities remains to be clarified after the formation of a surface layer of precipitated $\mathrm{Mg}$ corrosion products (namely $\mathrm{Mg}(\mathrm{OH})_{2}$ ) with the progress of the corrosion process. A recent proposal suggests the formation of an iron-rich precipitated layer on the surface of corroding magnesium alloys, which will result in an increase of the surface area for the cathodic halfcell reaction [14-16]. Alternatively, the enhanced catalytic surface theory (ECS) has been developed which gives a new explanation of the anomalous hydrogen evolution during anodic polarization. This theory postulates that the enhanced hydrogen evolution is due to the 
catalytic activity of either the $\mathrm{MgO} / \mathrm{Mg}(\mathrm{OH})_{2}$ bilayer formed in the anodic reaction [17-19] or the actively dissolving anodic regions [20-25]. Some recent experimental findings are supporting the proposals involved in this mechanism [12]. Thus, from the galvanostatic application of an increased sequence of anodic current densities to magnesium, followed by polarization of the sample to sufficiently negative potential and measurement of the cathodic current, Birbilis et al. observed that the cathodic current increased after increasing anodic polarization [26]. In another recent publication, Marco and Van der Biest used a rotating disc electrode to remove dissolving $\mathrm{Mg}^{2+}$ ions from the corroding magnesium surface, thus effectively reducing the thickness of the corrosion product layer developed at the surface of the metal as confirmed using surface analytical techniques [27]. Under increasing rotation speeds, smaller currents were recorded during the anodic potentiodynamic polarization of the metal sample, a feature supporting the involvement of the precipitated $\mathrm{Mg}(\mathrm{OH})_{2}$ layer in the mechanism responsible for the anomalous hydrogen evolution a pronounced, thus supporting the validity of the ECS theory. On the other hand, Taylor performed a first-principles surface reaction kinetic model for hydrogen evolution capable of satisfactorily reproducing the experimental observations of enhanced hydrogen evolution under cathodic and anodic conditions by considering only the actively corroding magnesium surface [28], that is, without involving the precipitation of $\mathrm{Mg}(\mathrm{OH})_{2}$ that may be regarded to passivate the surface both under cathodic and anodic polarizations. The proposed mechanism for the anomalous hydrogen evolution considers the reactive magnesium surface to provide adsorption sites for $\mathrm{OH}$, and the resulting $\mathrm{Mg}^{+} \mathrm{OH}$ sites can be removed through anodic dissolution of $\mathrm{Mg}$ as the $\mathrm{OH}$ accepts electrons and desorbs as $\mathrm{OH}^{-}$. An authoritative review of the recent experimental evidences and observations and the current opinions on the mechanism of magnesium corrosion has been contributed by Esmaily et al. [29].

Scanning electrochemical microscopy (SECM) has become an attractive tool for the study of heterogeneous reactions occurring at the solid-liquid phase boundary, therefore its application has been explored in the study of magnesium corrosion [30,31]. Although ion selective electrodes can be employed as potentiometric SECM probes to monitor specific ions related to the corrosion process (i.e., $\mathrm{Mg}^{2+}$ and hydrogen ions) [32-37], their general application is still limited by the electrical field developed in the electrolyte when polarization is applied to the metal [38-40]. As result, the most reliable procedure for measuring the corrosion rate of this metal under anodic polarization conditions using SECM is the amperometric operation. However, the oxygen reduction reaction is of little applicability for the monitoring of magnesium corrosion using amperometric SECM, and its use is effectively 
restricted to monitor the cathodic reaction in the case of galvanic coupling of magnesium with a more noble metal [41]. Neither redox conversion of magnesium ions is an option because the reduction potential of magnesium lies beyond the stability range of water [42]. Therefore, SECM imaging has to be based on the oxidation of hydrogen gas evolving from the corroding magnesium or magnesium alloy [35,43-49]. In this way, the amperometric SECM operation combined with shear force detection showed that the topography has an insignificant contribution to the current measured at the microelectrode tip for short exposures, so that the current changes were due exclusively to $\mathrm{H}_{2}$ evolution and could be directly correlated to the corrosion rate of the metal [44]. Furthermore, Jamali et al. demonstrated, using amperometric SECM detection, the higher electrochemical activity for the electron transfer reaction of those regions exhibiting the highest $\mathrm{H}_{2}$ evolution, thus implying that the metal was not covered by a surface film [43]. Furthermore, from the combination of AC-SECM operation and micropotentiometric $\mathrm{pH}$ detection, they concluded that anodic dissolution of magnesium should occur either at the same location or in close proximity to the high $\mathrm{H}_{2}$ evolution regions. Conversely, Salleh et al. showed enhanced $\mathrm{H}_{2}$ evolution above a $\mathrm{Mg}(\mathrm{OH})_{2}$ coated magnesium surface when using amperometric SECM operation [47]. Unfortunately, SECM operated amperometrically, using the sample generation - tip collection (SG/TC) mode during the oxidation of the hydrogen gas evolving from the corroding metal, suffers from severe convective effects caused on the measuring probe by gas evolution. As result the reproducibility and stability of the recorded faradaic currents while the magnesium substrate is anodically polarized are severely compromised [36].

In this work, we report a novel strategy for the scanning microelectrochemical study of hydrogen evolution from AZ63 magnesium alloy in aqueous $\mathrm{NaCl}$ solution either at the OCP or anodically polarized that was designed to explore the role of the surface film of $\mathrm{Mg}(\mathrm{OH})_{2}$ on the anomalous hydrogen evolution effect, and to evaluate the validity of the postulates of the enhanced catalytic surface theory (ECS) for magnesium based materials. In this method, the AZ63 magnesium alloy was subjected to a polarization routine for anodic activation that consists of a three-step (off-on-off) anodic polarization operation sequence in order to minimize the perturbation caused by $\mathrm{H}_{2}$ evolution on the current signals measured at the tip. In addition, spatially resolved $\mathrm{pH}$ and ionic flux distributions in the solution related to anodic polarization of the metal were monitored using potentiometric SECM and the scanning vibrating electrode technique (SVET) in order to supplement the observations obtained using amperometric SECM. 


\section{Experimental}

\subsection{Materials and electrodes}

Sodium chloride, magnesium-chloride hexahydrate, and disodium salt of ethylenediammin-tetraacetic acid (EDTA) were supplied by Merck (Darmstadt, Germany). Every solution was prepared using ultrapure water (resistivity, $18 \mathrm{M} \Omega \mathrm{cm}$; Millipore, Billerica, MA, USA).

The magnesium alloy samples were prepared from a sacrificial boiler anode made of AZ63 alloy. Rectangular base rods with about $1 \mathrm{~mm}^{2}$ cross section were cut from the anode and placed into a homemade cylindrical mount. The metal rods were embedded vertically in epoxy resin (EpofixKit, Struers, Denmark). The resulting circular samples with about $32 \mathrm{~mm}$ diameter were wet-ground to 4000 grit using a sequence of $\mathrm{SiC}$ abrasive papers, then polished with alumina slurries in ethanolic suspension down to $0.3 \mu \mathrm{m}$ size.

Pt microelectrodes (ME) with $25 \mu \mathrm{m}$ diameter (Goodfellow, Cambridge, UK) were employed in the amperometric SECM measurements. The detailed manufacturing protocol is described in Ref. [50]. In brief, a borosilicate capillary was first soaked in "Piranha" solution and subsequently rinsed with ultrapure water. Then, one end of the capillary was closed by heating it in the flame of a Bunsen burner. The Pt wire was introduced into the capillary positioned to the closed end, and melted the glass around it for an approximate 1-2 cm length. This process was performed while applying vacuum to the other end of the capillary in order to avoid any air bubbles to be left between the glass and the platinum wire in the melted section. The electrical connection was achieved by soldering a copper wire to the Pt wire in the lumen of the capillary. The sealed end was ground using $\mathrm{SiC}$ abrasive paper, until a ratio between the insulating shield thickness $(b)$ to the disc electrode radius $(a), R G=b / a$, smaller than $<10$ was achieved.

Preparation of the antimony microelectrodes followed the description in [33]. In brief, molten antimony powder (Aldrich, Saint Louis, MO, USA) was inserted the borosilicate capillaries while applying vacuum to the other end of the capillary. The resulting glass coated antimony wires were then subjected under capillary pulling processes. Antimony microwires with diameters between 10-20 $\mu \mathrm{m}$ were selected for microelectrode preparation. The antimony wires were attached to the opening of glass capillaries using a fast-drying bicomponent adhesive, and subsequently electrical connection was assured using liquid mercury and a copper wire. 


\subsection{SECM setup}

SECM experiments were performed using an instrument manufactured by Sensolytics (Bochum, Germany) and operated with an Autolab bipotentiostat (Metrohm Autolab BV, Utrecht, The Netherlands), all controlled with a personal computer. Amperometric area scans and line scans were performed using the $\mathrm{Pt} \mathrm{ME}$ biased at $-0.05 \mathrm{~V}$ vs. $\mathrm{Ag} / \mathrm{AgCl} /(3 \mathrm{M}) \mathrm{KCl}$ where hydrogen oxidation takes place. The electrochemical cell was completed with an $\mathrm{Ag} / \mathrm{AgCl} /(3 \mathrm{M}) \mathrm{KCl}$ electrode as reference $\left(E^{0}=+0.197 \mathrm{~V}\right.$ vs. NHE) and a Pt auxiliary electrode. In the case of potentiometric measurements, a homemade voltage follower based on a $10^{12} \Omega$ input impedance operational amplifier (mod. TL071, Texas Instruments, Dallas, TX, USA) was interconnected between the cell and the potentiometric input of the system. The samples were freshly polished before each measurement, and then laterally surrounded by Sellotape leaving a cylindrical compartment for about $4 \mathrm{~mL}$ volume of the test solution. The vertical tip-sample distance $(20 \mu \mathrm{m})$ was established using the gentle approach procedure with the aid of an optical microscope provided with a video camera. In this way, there was no need to add any redox mediator to the test solutions, and the scans could be started right after the solution was added to the cell. Besides, the feedback effects were thus eliminated, and the sample generation - tip collector mode was employed exclusively in the amperometric operation of the SECM.

\subsection{SVET setup}

The SVET instrument was supplied by Applicable Electronics Inc. (Forestdale, MA, USA). The components of the equipment are the preamplifier, PSDA-2, a Phase Sensitive Detector Amplifier operating as Lock-In Amplifier, motor controllers and an oscilloscope, all operated with a personal computer using ASET 2.00 software. The sensing probe was a $10 \mu \mathrm{m}$ PtIr tip with a black platinum deposit electrochemically grown to obtain the appropriate capacitance. The height of the scanning probe was placed at $50 \mu \mathrm{m}$ above the substrate, and $20 \mu \mathrm{m}$ amplitude probe vibrations were applied to the probe in both the normal and the parallel directions to the surface, with vibration frequencies of $78 \mathrm{~Hz}$ and $185 \mathrm{~Hz}$, respectively.

\section{Results and discussion}

As briefly described in the Introduction Section, the enhanced catalytic surface theory (ECS) postulates that either the uncoated reacting metal surface or a $\mathrm{Mg}(\mathrm{OH})_{2}$ layer should 
produce a catalytic effect on the evolution of hydrogen gas. If the $\operatorname{Mg}(\mathrm{OH})_{2}$ surface layer was influencing the kinetics of the HER then the following experimental effects should be observed:

1. The rate of the hydrogen evolution reaction (HER) will be enhanced after the formation of the $\operatorname{Mg}(\mathrm{OH})_{2}$ layer.

2. The rate of the HER will be enhanced if the electrolyte contains $\mathrm{Mg}^{2+}$ ions because formation of the $\mathrm{Mg}(\mathrm{OH})_{2}$ layer is favored.

3. Either removal or hindered formation of the $\mathrm{Mg}(\mathrm{OH})_{2}$ layer will decrease the rate of the HER.

4. Higher cathodic activity will occur from the $\mathrm{Mg}(\mathrm{OH})_{2}$-covered surface as the potential of the metal is polarized at a more positive potential.

The experiments described below were designed to explore the validity of theses expectations. By combining eq. (1) and (2), net equation (3) shows that the rate of the magnesium dissolution is directly proportional to the amount of hydrogen evolved:

$$
\mathrm{Mg}+2 \mathrm{H}_{2} \mathrm{O} \rightarrow \mathrm{Mg}(\mathrm{OH})_{2}+\mathrm{H}_{2}
$$

Then, the corrosion of magnesium in these experiments could be monitored by measuring hydrogen evolving from the sample using the sample generator - tip collector mode by setting the tip potential at $-0.05 \mathrm{~V}$ vs. $\mathrm{Ag} / \mathrm{AgCl} /(3 \mathrm{M}) \mathrm{KCl}$. In this way, the following cases could be differentiated: (i) the hydrogen released during the chemical reaction (3), (ii) the increased kinetics of the hydrogen evolution reaction on anodically "pre-polarised" surfaces - as inferred from cathodic polarisation tests [11,26,51], and (iii) the increased kinetics of the hydrogen evolution reaction on $\mathrm{Mg}(\mathrm{OH})_{2}$ covered or "coated" regions on $\mathrm{Mg}$, at OCP and also during cathodic polarization [47].

\subsection{Effect of anodic polarization on hydrogen evolution}

The generation of hydrogen from the AZ63 alloy immersed in $1 \mathrm{mM} \mathrm{NaCl}$ was first investigated with respect to the formation of a $\mathrm{Mg}(\mathrm{OH})_{2}$ layer on the surface of the material. A 3-step potential program was applied to the AZ63 sample using the bipotentiostat in the SECM instrument as drawn in the insets of Figure 1A and B. During the initial $30 \mathrm{~min}$ of exposure of the AZ63 sample in $1 \mathrm{mM} \mathrm{NaCl}$ solution, the alloy was allowed to spontaneously corrode at its OCP, whilst simultaneously measuring SECM line scans every 5 min with the Pt ME tip travelling across the sample $\left(E_{\text {tip }}=-0.05 \mathrm{~V}\right.$ vs. $\left.\mathrm{Ag} / \mathrm{AgCl} /(3 \mathrm{M}) \mathrm{KCl}\right)$ at $25 \mu \mathrm{m} \mathrm{s}^{-1} \mathrm{scan}$ rate. The line scans were collected along the same line, and the magnesium alloy sample was 
located between 1000 and $2000 \mu \mathrm{m}$ along the $X$ axis, whereas the remaining travelling distance was performed over the surrounding epoxy sleeve. Figure 1A shows the line scans recorded during the first stage of the potential program applied to the AZ63 alloy, whereas the inset of Figure 1A highlights in red the actual period of the potential program applied to the magnesium alloy at which the line scans were actually recorded. Time evolution of the tip current along the line scans with the elapse of time was readily observed. Smaller currents were recorded above the magnesium alloy in each subsequent scan, which could suggest that the evolution of hydrogen gas was progressively reduced from the corroding sample with the elapse of time as the catalytic effect occurring on the metal surface as result of the anodic polarization becomes progressively deactivated at the OCP.

After the initial $30 \mathrm{~min}$ period of the sample left at its OCP, the magnesium alloy was polarized at $-1.00 \mathrm{~V}$ vs. $\mathrm{Ag} / \mathrm{AgCl} /(3 \mathrm{M}) \mathrm{KCl}$ for another $30 \mathrm{~min}$. Vigorous hydrogen evolution could be observed from the system while the sample was subjected to anodic polarization. Once this $30 \mathrm{~min}$ period was completed, the polarization of the magnesium alloy was stopped, and the solution was stirred to remove any hydrogen bubbles (formed during the anodization period in the potential program) eventually adhered to the surface of the metal. Subsequently, another series of line scans were collected - along the same line as before - and they are shown in Figure 1B. From the comparison of the line scans depicted in Figure 1A and 1B, progressive decay of $\mathrm{H}_{2}$ evolution rates with the elapse of time was observed in both cases. However, the decay of hydrogen evolution occurred slower on the metal after it was subjected to anodic polarization for $30 \mathrm{~min}$. This fact can be observed in Figure 2, where the average current values corresponding to the plateaus occurring in the line scans of Figure 1 were plotted as a function of time. For the sake of reproducibility, the experiments were performed in triplicate, and the error bars in Figure 2 represent the variability observed in the measurements. Interestingly the logarithm of the average current values decreased linearly with time in both cases. Although these observed trends could not be considered to quantitatively represent the behavior of the complete exposed surface of the sample, because measurements were performed only along a certain line across it, the main finding is that the logarithmic function fitted satisfactorily the experimental data. The slope of the plot corresponding to the line scans recorded before the application of the anodic polarization step to AZ63 sample was $-0.13 \mathrm{~min}^{-1}$, whereas the slope recorded afterwards amounted -0.05 $\min ^{-1}$. This implies that hydrogen evolution increased after the formation of the hydroxide layer on the surface of the magnesium alloy. These observations complement those reported by Salleh et al. [47], although with the advantage that the 3-step polarization program applied 
to the sample allowed to compare in situ the variations in hydrogen evolution during the same run.

The potential dependence of this phenomenon was further investigated by applying 3 different potential values to a freshly prepared sample, namely $-1.1,-1.0$, and $-0.9 \mathrm{~V}$ vs. $\mathrm{Ag} / \mathrm{AgCl} /(3 \mathrm{M}) \mathrm{KCl}$. In this experiment the sample was not polished between the measurements, that is, the 3 anodic polarizations and subsequent recording of the SECM line scans on the non-polarized sample were carried out one after the other. In addition, the duration of the first two steps of the polarization program applied to the AZ63 sample was reduced to $10 \mathrm{~min}$, and the SECM line scans of $\mathrm{H}_{2}$ fluxes were taken every $5 \mathrm{~min}$ over the same line across the metal. The slope of the logarithm of average tip currents with time (i.e., decay of the generation rate of hydrogen) did not show a clear dependence on the applied anodic potential for small anodic polarizations: namely, $0.032 \mathrm{~min}^{-1}$ after the sample was polarized at $-1.1 \mathrm{~V}$ vs. $\mathrm{Ag} / \mathrm{AgCl} /(3 \mathrm{M}) \mathrm{KCl}$, and $0.030 \mathrm{~min}^{-1}$ after the sample was biased at $-1.00 \mathrm{~V}$ vs. $\mathrm{Ag} / \mathrm{AgCl} /(3 \mathrm{M}) \mathrm{KCl}$. However, a faster decay was observed when the SECM line scans were recorded after the magnesium alloy was polarized at $-0.9 \mathrm{~V}$ vs. $\mathrm{Ag} / \mathrm{AgCl} /(3 \mathrm{M})$ $\mathrm{KCl}$. In this case, the slope amounted $0.044 \mathrm{~min}^{-1}$. But even in this case, the slope is significantly smaller than the slope corresponding to the initial exposure to the solution, prior to the application of the anodic polarization (cf. black line in Figure 2). Therefore, these results evidence that the hydrogen evolution recorded by the SECM tip strongly depends on the magnitude of the prior anodic dissolution process during the polarization step, as it would be expected on the basis of the enhanced catalytic surface theory (ECS) due to anodic dissolution [20].

The enhanced $\mathrm{H}_{2}$ evolution after anodic polarization was further characterized from a sequence of microphotographs taken during an independent experiment, which is shown in Figure 3. The freshly polished sample placed at the bottom of the SECM small cell prior to the addition of the $1 \mathrm{mM} \mathrm{NaCl}$ solution can be seen in Figure 3A. Figure 3B shows the micrograph taken immediately after the saline solution was added to the cell, while Figure $3 \mathrm{C}$ depicts the state of the system immediately after the anodic polarization was stopped. The greater $\mathrm{H}_{2}$ fluxes from the magnesium alloy following anodic polarization are readily observable, although the OCP values did not change significantly from those recorded prior to the application of the anodic polarization. The increased fluxes of hydrogen gas are in good agreement with the SECM experiments. During the anodic polarization stage, an increased rate of $\mathrm{Mg}^{2+}$ dissolution can be observed, which results in the formation of a thicker layer of magnesium oxi-hydroxide. 


\subsection{Effect of $\mathrm{Mg}^{2+}$ ion concentration on hydrogen evolution}

The findings of the experiments described in the previous section can be attributed to the presence of a layer of corrosion products that might produce a catalytic effect on the HER. Accordingly, by enhancing the formation of the catalytic layer, $\mathrm{H}_{2}$ evolution will be accelerated. To prove this hypothesis, SECM maps were recorded above the corroding surface of AZ63 magnesium alloy immersed in $1 \mathrm{mM} \mathrm{NaCl}+1 \mathrm{mM} \mathrm{MgCl}_{2}$, that is, in a solution containing dissolved $\mathrm{Mg}^{2+}$ ions. According to eqn. (2), with the progress of the metal corrosion reaction, the cathodic reaction will cause alkalinization in the solution volume adjacent to the metal. Since the $\mathrm{pH}$ is expected to reach the highest values in the very close

proximity of the sample, in a solution containing $1 \mathrm{mM}$ concentration of $\mathrm{Mg}^{2+}$ ions, formation of the oxi-hydroxide layer will be enhanced by precipitation from the solution. The SECM maps of the hydrogen fluxes arising from the corroding alloy at its OCP are shown in Figure 4. Due to the increased chloride concentration in the test solution, the experiments were repeated in $3 \mathrm{mM} \mathrm{NaCl}$ solution for comparison. Differences in the rates of HER from AZ63 samples immersed in the two electrolytes could be directly observed from the SECM maps. It was found that higher fluxes of hydrogen gas were recorded when the magnesium alloy was immersed in a solution containing $\mathrm{Mg}^{2+}$ ions. In addition, when the experiment was repeated on freshly prepared AZ63 samples using the Sb-based ME for SECM operated in the potentiometric mode, differences in $\mathrm{pH}$ were observed between the samples immersed in either electrolyte as shown in Figure 5. It was found that the $\mathrm{pH}$ above the corroding metal was higher by 0.5 units when it was immersed in the solution containing $\mathrm{MgCl}_{2}$, a fact consistent with the higher rate of the HER in this case. Although only a few selected images are shown here, the SECM experiments were repeated several times as to derive reproducible observations from the data.

At this point, no definitive explanation can be given regarding the current decrease with the elapse of time shown in Figure 2. Since the eventuality of the Pt microelectrode undergoing changes at its surface after recording a series of line scans could be discarded by recording cyclic voltammograms at the tip when placed in the bulk of the electrolyte, the possibility of some surface passivation of the corroding magnesium alloy could be considered. But this observation would therefore contradict the previous observation that hydrogen evolution increased upon formation of the hydroxide layer on the surface of the sample during anodic polarization therefore acting as a catalyst for $\mathrm{H}_{2}$ evolution. Therefore, it may be considered that $\mathrm{Mg}(\mathrm{OH})_{2}$ plays a dual role: it is a catalyst for $\mathrm{H}_{2}$ evolution, but it also 
passivates $\mathrm{Mg}$ to some extent as to explain the decrease of the $\mathrm{H}_{2}$ evolution rate for longer exposure times. That is, the catalytic effect and the passivation would be competitive processes for the HER. But the decrease of the current may be consistent with the assumption that the $\mathrm{Mg}$ (and $\mathrm{Al}, \mathrm{Zn}$ ) oxides cover the magnesium surface, slowing the hydrogen evolution, a feature that is consistent with reports showing that $\mathrm{Al}$ enrichment decreases the corrosion rate in immersion tests of AM50 and AM60 Mg alloy series [35,44,52]. On the other hand, one could question the role of aluminum and zinc contents in the alloy [53]. In principle, the main difference should be the amount of $\mathrm{Mg}(\mathrm{OH})_{2}$ formed on the surface of the alloy during the anodic polarization stage because the line scans were recorded under the same experimental conditions apart from controlled variations in the potential of the anodic polarization. But $\mathrm{Al}$ and $\mathrm{Zn}$ enrichment in the hydroxide layer due to preferential dissolution of magnesium would account for a greater passivation effect, since the hydroxides of these more noble elements will not increase the rate of the HER contrary to $\mathrm{Mg}(\mathrm{OH})_{2}$. Finally, an alternate explanation has been proposed above where the kinetics of reaction (3) could decrease with time, as the system may tend towards an equilibrium after the anodic polarisation step due to ceasing the catalytic activation associated to it.

The eventual passivating role of the hydroxide layer was further investigated by recording amperometric SECM map scans similar to those described in Figure 4, but using significantly higher electrolyte concentrations this time. The rationale was to mitigate to some degree the extent of the increased HER effect observed when adding $\mathrm{MgCl}_{2}$ to a dilute $\mathrm{NaCl}$ solution. As it can be seen in Figure 6, a different behaviour was observed this time. After 1 hour exposure to either $0.2 \mathrm{M} \mathrm{NaCl}$ or $0.1 \mathrm{M} \mathrm{MgCl}_{2}$ solutions, the HER became slower when a thicker hydroxide layer was formed on the surface of the AZ63 alloy, as it was the case in the $\mathrm{MgCl}_{2}$ containing solution.

\subsection{Effect of a complexing agent for $\mathrm{Mg}^{2+}$ ion on hydrogen evolution}

It has been already shown what happens when formation of the $\mathrm{Mg}$ oxi-hydroxide layer is promoted. Analogously, if the formation of this layer were hindered, less $\mathrm{H}_{2}$ should be generated from the corroding metal. Since dissolution of the surface oxi-hydroxide bilayer in acidic media would also increase the dissolution reaction of the magnesium alloy with the generation of hydrogen gas, the observations could not be unambiguously assigned to the removal of the surface anodic film. Hence, complexation of the $\mathrm{Mg}^{2+}$ ions appeared to be a more adequate method, because it would cause a smaller perturbation of the system under investigation. Ethylene diamine tetra-acetic acid (EDTA) is a complexant widely used in 
complexometric titration of $\mathrm{Mg}^{2+}$ containing samples. The classic titration is performed in alkaline solution ( $\mathrm{pH}=10)$, a fact implying that complexation with the metal ions is very fast even in alkaline solution. During the corrosion of AZ63 in $1 \mathrm{mM} \mathrm{NaCl}$ solution, the $\mathrm{pH}$ should rarely reach above this value as shown in Figure 5, and hence it is expected that the complexation reaction will happen to a greater extent than precipitation of the oxi-hydroxide layer. In other words, EDTA would capture the $\mathrm{Mg}^{2+}$ ions dissolving from the corroding AZ63 sample, hindering the formation of the catalytic layer. Thinner surface oxide films formed on $\mathrm{Mg}$ in the presence of EDTA in the chloride-containing solution have been observed using EIS and Raman Spectroscopy [54]. Additionally, Williams et al. have reported that the rate of $\mathrm{Mg}$ corrosion was greatly diminished in $1 \mathrm{M} \mathrm{NaCl}$ solution in the presence of EDTA, and it was accompanied by a change in the appearance of the corroding surface [55].

The SECM maps of the hydrogen fluxes arising from the corroding alloy at its OCP during immersion in $1 \mathrm{mM} \mathrm{NaCl}$ both in the absence and in the presence of $10 \mathrm{mM}$ EDTA are shown in Figure 7. For the sake of better comparison, the same color scale was employed in both maps, although the high current values in Figure 7B cannot be resolved using this color palette. In order to overcome this limitation, labeled contours have been drawn in both maps in Figure 7. In the case of the AZ63 sample immersed in $1 \mathrm{mM} \mathrm{NaCl}$ solution in the absence of the complexant, current values amounting 4-5 nA were recorded at certain sites, whereas the highest current measured in the solution containing EDTA amounted only $1.5 \mathrm{nA}$. That is, in the presence of EDTA, a significantly lower generation of $\mathrm{H}_{2}$ gas occurred, which implies that the $\mathrm{Mg}(\mathrm{OH})_{2}$ layer must play an important role in the process of hydrogen generation from anodically polarized magnesium materials. Using the $\mathrm{Sb} / \mathrm{Sb}_{2} \mathrm{O}_{3}$ tip, the eventual development of a significant $\mathrm{pH}$ difference between the surfaces of the alloy samples immersed in the two solutions was explored. However, the $\mathrm{pH}$ changes between the two maps remained smaller than $0.3 \mathrm{pH}$ units (not shown), thus the effect of $\mathrm{pH}$ changes was regarded to be negligible in this experiment.

In Figure 8, a similar set of SECM maps of hydrogen fluxes are shown for AZ63 samples immersed in $1 \mathrm{mM} \mathrm{NaCl}$ both in the absence and in the presence of $10 \mathrm{mM}$ EDTA, although in this case magnesium alloys were anodically polarized at $-1.0 \mathrm{~V}$ vs. $\mathrm{Ag} / \mathrm{AgCl} /(3$ M) KCl. Again, the amount of hydrogen gas generated from the sample immersed in the solution containing EDTA was significantly smaller than in its absence. It is noteworthy that the SECM map for hydrogen fluxes shown in Figure 8A (i.e., for the anodically polarized AZ63 sample in the solution containing $10 \mathrm{mM}$ EDTA) is fairly similar to the SECM map given in Figure 7B, corresponding to an AZ63 sample spontaneously corroding at the OCP in 
$1 \mathrm{mM} \mathrm{NaCl}$ solution. This implies that for the magnesium alloy immersed in the solution containing EDTA to attain a similar hydrogen evolution rate as it spontaneously produced in the test electrolyte, a relatively high anodic polarization had to be imposed to the sample. In the presence of EDTA (Figure 8A), the highest current values measured above the anodized magnesium were 4-6 nA, although they were observed only at a few sites over the surface, and could correspond to the accumulation of hydrogen bubbles. However, in the absence of EDTA (cf. Figure 8B), the 4-6 nA values for the hydrogen oxidation current were measured above the complete sample. This indirectly indicates that, the suppression of the oxide/hydroxide layer reduced the rate of hydrogen gas generation, as well. Therefore, the results described are complementary to the preliminary results reported by Williams et al. on the EDTA complexation effects of $\mathrm{Mg}^{2+}$ ions during $\mathrm{Mg}$ corrosion that were observed using SVET [55].

So far, the reduced HER from AZ63 magnesium alloy in the presence of EDTA has been analysed considering that a thinner hydroxide layer is formed. An alternate explanation would be to consider EDTA acting as a hydrogen recombination poison [56]. Therefore, a new series of experiments was performed by considering a $\operatorname{Mg}(\mathrm{OH})_{2}$ layer deposited on nickel from a $\mathrm{MgCl}_{2} / \mathrm{Mg}\left(\mathrm{NO}_{3}\right)_{2}$ containing solution as proposed in Ref. [57]. Once the $\mathrm{Mg}(\mathrm{OH})_{2}$ layer was deposited, the sample was washed and dried in air and an optical photograph was taken of the sample (see Figure 9). Then 0.01 M EDTA solution was added to the cell and it was allowed to react for $5 \mathrm{~min}$. Afterwards, the sample was washed and dried in air. The different appearances of the coated sample prior and after exposure to a solution containing EDTA can be readily seen by comparing the photographs in Figures 9B and 9C. In summary, a less dense surface hydroxide layer is expected to be formed in the presence of EDTA, similarly to what has been observed on Ni [57].

\subsection{SVET measurements on anodically polarized AZ63 magnesium alloy}

The Scanning Vibrating Electrode Technique (SVET) was employed to detect local anodic and cathodic activities above the cathodically and anodically polarized magnesium alloy sample for comparison with the behavior of material spontaneously corroding at it OCP.

Figure 10 shows a typical Tafel plot of AZ63 immersed in $1 \mathrm{mM} \mathrm{NaCl}$. The OCP was $-1.40 \mathrm{~V}$ vs. $\mathrm{Ag} / \mathrm{AgCl} /(3 \mathrm{M}) \mathrm{KCl}$ prior to the measurement, but during the polarization experiment it shifted to slightly above $-1.3 \mathrm{~V}$ vs. $\mathrm{Ag} / \mathrm{AgCl} /(3 \mathrm{M}) \mathrm{KCl}$. The shift to a more positive value resulted from the reduction of the air-formed oxide originally present on the surface of the alloy during the cathodic branch of the polarization measurement. 
The SVET measurements were carried out on freshly prepared samples. Different potential values were applied to the alloy in order to cover a range of both cathodic and anodic polarizations, namely $-1.70 \mathrm{~V}$ vs. $\mathrm{Ag} / \mathrm{AgCl} /(3 \mathrm{M}) \mathrm{KCl}$ for cathodic polarization, -1.30 $\mathrm{V}$ vs. $\mathrm{Ag} / \mathrm{AgCl} /(3 \mathrm{M}) \mathrm{KCl}$ for a weak anodic polarization, and $-1.00 \mathrm{~V}$ vs. $\mathrm{Ag} / \mathrm{AgCl} /(3 \mathrm{M})$ $\mathrm{KCl}$ for an anodic polarization comparable to those employed in the SECM experiments described above. The corresponding current density maps are shown in Figure 11. In the first map, taken above the sample biased at $-1.7 \mathrm{~V}$ vs. $\mathrm{Ag} / \mathrm{AgCl} /(3 \mathrm{M}) \mathrm{KCl}$, the complete sample behaved as a big cathode delivering negative ionic currents from the surface of the metal towards to the electrolyte. At the OCP, metal dissolution started from the right edge of the sample, and both anodic and cathodic regions were distributed over the surface of the material. Polarization of the sample anodic to the OCP resulted in an increase of the anodic activity associated to positive ionic currents as expected, although more interestingly, an apparent cathodic behavior was also enhanced related to the measurement of negative current densities. Indeed, they actually correspond to the diffusion of $\mathrm{OH}^{-}$anions from the surface, as result of hydrogen generation according to reaction (3). Finally, at $-1.0 \mathrm{~V}$ vs. $\mathrm{Ag} / \mathrm{AgCl} /(3 \mathrm{M})$ $\mathrm{KCl}$, the anodic character of the sample largely prevailed in the ionic current density map, however local observations of the apparent cathodic activity were found. Furthermore, the values associated to the release of $\mathrm{OH}^{-}$ions were greater than those previously observed at the OCP (cf. Figures 11B and 11D). Since the SVET technique is not chemically-selective, the potential differences measured at the vibrating tip resulted from both metal dissolution and catalytically enhanced hydrogen evolution. Therefore, with the application of an anodic polarization to the AZ63 sample immersed in $1 \mathrm{mM} \mathrm{NaCl}$, the rate of $\mathrm{Mg}^{2+}$ dissolution increased as indicated by bigger positive ionic current densities recorded from the system, although this occurred in combination with the observation of negative ionic current densities from the corroding surface. This implies that cathodic activity occurred on the anodically polarized sample. These observations are in good agreement with reports by Williams and McMurray using SVET [18].

The SVET results described here are a good support for the validity of the 3-step potential program applied to the AZ63 sample during SECM operation in the sample generation-tip collection mode. Variations in the amount of evolving hydrogen measured during the "off-on-off" sequence can be effectively correlated to the formation of a corrosion product surface film over the corroding material under anodic polarization. This procedure is thus an extension of previous hydrogen mapping characterizations using amperometric SECM of AZ31 [43], AZNd [45,46,48] and AM50 [35,44] magnesium alloys, that were typically 
conducted while the samples were left at their corresponding OCP values in the environment. Furthermore, the authors regard the use of this 3-step polarization sequence that includes an intermediate anodic polarization step to be an promising experimental procedure to be employed to characterize pure magnesium as well, and hope that the evidences reported here can contribute relevant experimental data to the lingering debates on the catalytic behavior of the precipitated surface film mainly composed by $\mathrm{Mg}(\mathrm{OH})_{2}$.

\section{Conclusions}

SECM and SVET experiments provided in situ information on the influence of surface film formation on magnesium-based materials towards hydrogen evolution. Hydrogen evolution resulting from anodic polarization of the magnesium alloy can monitored with high spatial resolution using the sample generation-tip collection mode of SECM by using a 3-step polarization sequence, effectively circumventing the convective effects due to the vigorous formation of hydrogen bubbles that occurs when direct anodic polarization is performed instead.

In this work, increased rates for hydrogen evolution were observed after the growth of the $\mathrm{Mg}(\mathrm{OH})_{2}$ layer on the AZ63 magnesium alloy surface by anodic polarization. Furthermore, the addition of $\mathrm{Mg}^{2+}$ ions to the test electrolyte yielded greater generation of hydrogen gas, whereas the removal of the $\mathrm{Mg}(\mathrm{OH})_{2}$ layer with supposed catalytic layer resulted in significantly less $\mathrm{H}_{2}$ formation when EDTA, a strong complexant of $\mathrm{Mg}^{2+}$ ions, was added to the electrolyte. Therefore, the kinetics of the HER was found to be higher over the anodised areas.

\section{Acknowledgements}

D. Filotás expresses his greatest gratitude to the ERASMUS+ program for the financial support of a 2-month mobility grant to the University of La Laguna. B.M. Fernández-Pérez is grateful to the Canarian Agency for Research, Innovation and Information Society (Las Palmas de Gran Canaria, Spain) and the European Social Fund (Brussels, Belgium) for a research contract. Financial support by the Spanish Ministry of Economy and Competitiveness (MINECO, Madrid) and the European Regional Development Fund, under grant CTQ2016-80522-P, The National Research, Development and Innovation Office (Budapest, Hungary) under grant K125244, and the "Environmental industry related innovative trans- and interdisciplinary research team development in the University of Pécs 
knowledge base under SROP-4.2.2.D-15/1/Konv-2015-0015 project is gratefully acknowledged.

\section{References}

1. G. Song, Recent progress in corrosion and protection of magnesium alloys, Adv. Eng. Mater.7 (2005) 563-586.

2. E. Ghali, W. Dietzel, K.U. Kainer, General and localized corrosion of magnesium alloys: a critical review, J. Mater. Eng. Perform. 13 (2004) 7-23.

3. N.T. Kirkland, N. Birbilis, M.P. Staiger, Assessing the corrosion of biodegradable magnesium implants: A critical review of current methodologies and their limitations, Acta Biomater. 8 (2012) 925 -936.

4. S. Lebouil, A. Duboin, F. Monti, P. Tabeling, P. Volovitch, K. Ogle, A novel approach to on-line measurement of gas evolution kinetics: application to the negative difference effect of Mg in chloride solution, Electrochim. Acta 124 (2014) 176-182.

5. L. Rossrucker, K.J.J. Mayrhofer, G.S. Frankel, N. Birbilis, Investigating the real time dissolution of Mg using online analysis by ICP-MS, J. Electrochem. Soc. 161 (2014) C115-C119.

6. Z.M. Shi, J.X. Jia, A.Atrens, Galvanostatic and anodic polarisation curves and galvanic corrosion of high purity $\mathrm{Mg}$ in $3.5 \% \mathrm{NaCl}$ saturated with $\mathrm{Mg}(\mathrm{OH})_{2}$, Corros. Sci. 60 (2012) 296-308.

7. G. Song, A. Atrens, D. StJohn, X. Wu, J. Nairn, Y. Li, The electrochemical corrosion of pure magnesium in $1 \mathrm{~N} \mathrm{NaCl}$, Corros. Sci. 39 (1997) 855-875.

8. A. Atrens, W. Dietzel, The negative difference effect and unipositive $\mathrm{Mg}^{+}, \mathrm{Adv}$. Eng. Mater. 9 (2007) 292-297.

9. R.L. Petty, A.W. Davidson, J. Kleinberg, The anodic oxidation of magnesium metal: evidence for the existence of unipositive magnesium, J. Am. Chem. Soc. 76 (1954) 363366.

10. A. Samaniego, B.L. Hurley, G.S. Frankel, On the evidence for univalent Mg, J. Electroanal. Chem. 737 (2015) 123-128.

11. M. Curioni, The behavior of magnesium during free corrosion and potentiodynamic polarization investigated by real-time hydrogen measurement and optical imaging, Electrochim. Acta 120 (2014) 284-292. 
12. S. Thomas, N.V. Medhekar, G.S. Frankel, N. Birbilis, Corrosion mechanism and hydrogen evolution on Mg, Curr. Opin. Solid State Mater. Sci. 19 (2015) 85-94.

13. J.D. Hanawalt, C.E. Nelson, J.A. Peloubet, Corrosion studies of magnesium and its alloys, Trans. AIME 147 (1942) 273-299.

14. D. Höche, C. Blawert, S.V. Lamaka, N. Scharnagl, C. Mendis, M.L. Zheludkevich, The effect of iron re-deposition on the corrosion of impurity-containing magnesium, Phys. Chem. Chem. Phys. 18 (2016) 1279-1291.

15. S.V. Lamaka, D. Höche, R.P. Petrauskas, C. Blawert, M.L. Zheludkevich, A new concept for corrosion inhibition of magnesium: Suppression of iron re-deposition, Electrochem. Commun. 62 (2016) 5-8.

16. J. Yang, C. Blawert, S.V. Lamaka, K.A. Yasakau, L. Wang, D. Laipple, M. Schieda, S. Di, M.L. Zheludkevich, Corrosion inhibition of pure Mg containing a high level of iron impurity in pH neutral $\mathrm{NaCl}$ solution, Corros. Sci. 142 (2018) 222-237.

17. G. Williams, N. Birbilis, H.N. McMurray, The source of hydrogen evolved from a magnesium anode, Electrochem. Commun. 36 (2013) 1-5.

18. G. Williams, H.N. McMurray, Localized corrosion of magnesium in chloride-containing electrolyte studied by a scanning vibrating electrode technique, J. Electrochem. Soc. 155 (2008) 340-349.

19. M. Taheri, J.R. Kish, N. Birbilis, M. Danaie, E.A. McNally, J.R. McDermid, Towards a physical description for the origin of enhanced catalytic activity of corroding magnesium surfaces, Electrochim. Acta 116 (2014) 396-403.

20. G.S. Frankel, A. Samaniego, N. Birbilis, Evolution of hydrogen at dissolving magnesium surfaces, Corros. Sci. 70 (2013) 104-111.

21. S. Fajardo, G.S. Frankel, Gravimetric method for hydrogen evolution measurements on dissolving magnesium, J. Electrochem. Soc. 162 (2015) C693-C701.

22. S. Fajardo, C.F. Glover, G. Williams, G.S. Frankel, The source of anodic hydrogen evolution on ultra high purity magnesium, Electrochim. Acta 212 (2016) 510-521.

23. S. Fajardo, G.S. Frankel, A kinetic model explaining the enhanced rates of hydrogen evolution on anodically polarized magnesium in aqueous environments, Electrochem. Commun. 84 (2017) 36-39.

24. M. Curioni, J.M. Torrescano-Alvarez, Y.F. Yang, F. Scenini, Application of side-view imaging and real-time hydrogen measurement to the investigation of magnesium corrosion, Corrosion 73 (2017) 463-470. 
25. M. Curioni, L. Salamone, F. Scenini, M. Santamaria, M. Di Natale, A mathematical description accounting for the superfluous hydrogen evolution and the inductive behaviour observed during electrochemical measurements on magnesium, Electrochim. Acta 274 (2018) 343-352.

26. N. Birbilis, A.D. King, S. Thomas, G.S. Frankel, J.R. Scully, Evidence for enhanced catalytic activity of magnesium arising from anodic dissolution, Electrochim. Acta 132 (2014) 277-283.

27. I. Marco, O. Van der Biest, Polarization measurements from a rotating disc electrode for characterization of magnesium corrosion, Corros. Sci. 102 (2015) 384-393.

28. C.D. Taylor, A first-principles surface reaction kinetic model for hydrogen evolution under cathodic and anodic conditions on Mg, J. Electrochem. Soc. 163 (2016) C602C608.

29. M. Esmaily, J.E. Svensson, S. Fajardo, N. Birbilis, G.S. Frankel, S. Virtanen, R. Arrabal, S. Thomas, L.G. Johansson, Fundamentals and advances in magnesium alloy corrosion, Prog. Mater. Sci. 89 (2017) 92-193.

30. S. Thomas, J. Izquierdo, N. Birbilis, R.M. Souto, Possibilities and limitations of scanning electrochemical microscopy of $\mathrm{Mg}$ and $\mathrm{Mg}$ alloys, Corrosion 71 (2015) 171-183.

31. P. Dauphin-Ducharme, J Mauzeroll, Surface analytical methods applied to magnesium corrosion, Anal. Chem. 87 (2015) 7499-7509.

32. R.M. Souto, A. Kiss, J. Izquierdo, L. Nagy, I. Bitter, G. Nagy, Spatially-resolved imaging of concentration distributions on corroding magnesium-based materials exposed to aqueous environments by SECM, Electrochem. Commun. 26 (2013) 25-28.

33. J. Izquierdo, L. Nagy, I. Bitter, R.M. Souto, G. Nagy, Potentiometric scanning electrochemical microscopy for the local characterization of the electrochemical behaviour of magnesium-based materials, Electrochim. Acta 87 (2013) 283-293.

34. J. Izquierdo, A. Kiss, J.J. Santana, L. Nagy, I. Bitter, H.S. Isaacs, G. Nagy, R.M. Souto, Development of $\mathrm{Mg}^{2+}$ ion-selective microelectrodes for potentiometric scanning electrochemical microscopy monitoring of galvanic corrosion processes, J. Electrochem. Soc. 160 (2013) C451-C459.

35. P. Dauphin-Ducherme, R.M. Asmussen, D.W. Shoesmith, J. Mauzeroll, In-situ $\mathrm{Mg}^{2+}$ release monitored during magnesium alloy corrosion, J. Electroanal. Chem. 736 (2015) 61-68.

36. J. Izquierdo, B.M. Fernández-Pérez, D. Filotás, Z. Öri, A. Kiss, R.T. Martín-Gómez, L. Nagy, G. Nagy, R.M. Souto, Imaging of concentration distributions and hydrogen 
evolution on corroding magnesium exposed to aqueous environments using scanning electrochemical microscopy, Electroanalysis 28 (2016) 2354-2366.

37. S.H. Salleh, N. Birbilis, M. Musameh, K. Venkatesan, S. Thomas, On the development and application of an in-house fabricated $\mathrm{Mg}^{2+}$ ion selective microelectrode (ISME) for assessing Mg corrosion, J. Electrochem. Soc. 165 (2018) C771-C776.

38. A. Kiss, D. Filotás, R.M. Souto, G. Nagy, The effect of electric field on potentiometric scanning electrochemical microscopic imaging, Electrochem. Commun. 77 (2017) 138141.

39. D. Filotás, B.M. Fernández-Pérez, A. Kiss, L. Nagy, G. Nagy, R.M. Souto, Double barrel microelectrode assembly to prevent electrical field effects in potentiometric SECM imaging of galvanic corrosion processes, J. Electrochem. Soc. 165 (2018) C270-C277.

40. D. Filotás, B.M. Fernández-Pérez, L. Nagy, G. Nagy, R.M. Souto, Multi-barrel electrodes containing an internal micro-reference for the improved visualization of the galvanic corrosion of magnesium using potentiometric SECM, Sensor. Actuat. B-Chem. 296 (2019) 126625, 10 pp.

41. A. Simões, D. Battocchi, D. Tallman, G. Bierwagen, Assessment of the corrosion protection of aluminium substrates by a Mg-rich primer: EIS, SVET and SECM study, Prog. Org. Coat. 63 (2008) 260-266.

42. J.A. Yuwono, N. Birbilis, C.D. Taylor, K.S. Williams, A.J. Samin, N.V. Medhekar, Aqueous electrochemistry of the magnesium surface: Thermodynamic and kinetic profiles, Corros. Sci. 147 (2019) 53-68.

43. S.S. Jamali, S.E. Moulton, D.E. Tallman, M. Forsyth, J. Weber, G.G. Wallace, Applications of scanning electrochemical microscopy (SECM) for local characterization of AZ31 surface during corrosion in a buffered media, Corros. Sci. 86 (2014) 93-100.

44. U.M. Tefashe, M.E. Snowden, P.D. Ducharme, M. Danaie, G.A. Botton, J. Mauzeroll, Local flux of hydrogen from magnesium alloy corrosion investigated by scanning electrochemical microscopy, J. Electroanal. Chem. 720-721 (2014) 121-127.

45. S.S. Jamali, S.E. Moulton, D.E. Tallman, M. Forsyth, J. Weber, A. Mirabedini, G.G. Wallace, Corrosion protection afforded by praseodymium conversion film on $\mathrm{Mg}$ alloy AZNd in simulated biological fluid studied by scanning electrochemical microscopy, J. Electroanal. Chem. 739 (2015) 211-217.

46. S.S. Jamali, S.E. Moulton, D.E. Tallman, M. Forsyth, J. Weber, G.G. Wallace, Evaluating the corrosion behaviour of magnesium alloy in simulated biological fluid by using SECM to detect hydrogen evolution, Electrochim. Acta 152 (2015) 294-301. 
47. S.H. Salleh, S. Thomas, J.A. Yuwono, K. Venkatesan, N. Birbilis, Enhanced hydrogen evolution on $\mathrm{Mg}(\mathrm{OH})_{2}$ covered $\mathrm{Mg}$ surfaces, Electrochim. Acta 161 (2015) 144-152.

48. S.S. Jamali, S.E. Moulton, D.E. Tallman, Y. Zhao, J. Weber, G.G. Wallace, Self-healing characteristics of praseodymium conversion coating on $\mathrm{AZNd} \mathrm{Mg}$ alloy studied by scanning electrochemical microscopy, Electrochem. Commun. 76 (2017) 6-9.

49. E. Mena-Morcillo, L.P. Veleva, D.O.Wipf, Multi-scale monitoring the first stages of electrochemical behavior of AZ31B magnesium alloy in simulated body fluid, J. Electrochem. Soc. 165 (2018) C749-C755.

50. C. Kranz, M. Ludwig, H.E. Gaub, W. Schuhmann, Lateral deposition of polypyrrole lines by means of the scanning electrochemical microscope, Adv. Mat. 7 (1995) 38-40.

51. J. Swiatowska, P. Volovitch, K. Ogle, The anodic dissolution of $\mathrm{Mg}$ in $\mathrm{NaCl}$ and $\mathrm{Na}_{2} \mathrm{SO}_{4}$ electrolytes by atomic emission spectroelectrochemistry, Corros. Sci. 52 (2010) 23722378 .

52. M.C. Zhao, P. Schmutz, S. Brunner, M. Liu, G.L. Song, A. Atrens, An exploratory study of the corrosion of magnesium alloys during interrupted salt spray testing, Corros. Sci. 51 (2009) 1277-1292.

53. S. Fajardo, J. Bosch, G.S. Frankel, Anomalous hydrogen evolution on AZ31, AZ61 and AZ91 magnesium alloys in unbuffered sodium chloride solution, Corros. Sci. 146 (2019) 163-171.

54. L.G. Bland, K. Gusieva, J.R. Scully, Effect of crystallographic orientation on the corrosion of magnesium: comparison of film forming and bare crystal facets using electrochemical impedance and Raman spectroscopy, Electrochim. Acta 227 (2017) 136151.

55. G. Williams, R. Subramanian, C.F. Glover, S. John, H.N. McMurray, The use of EDTA as a mechanistic probe of magnesium corrosion in chloride containing electrolyte, Meeting Abstract, The Electrochem. Soc. MA2015-02 (2015) 657, 3 pp.

56. G.S. Frankel, private communication.

57. G.H.A. Therese, P.V. Kamath, Cathodic reduction of different metal salt solutions Part I: synthesis of metal hydroxides by electrogeneration of base, J. Appl. Electrochem. 28 (1998) 539-543. 

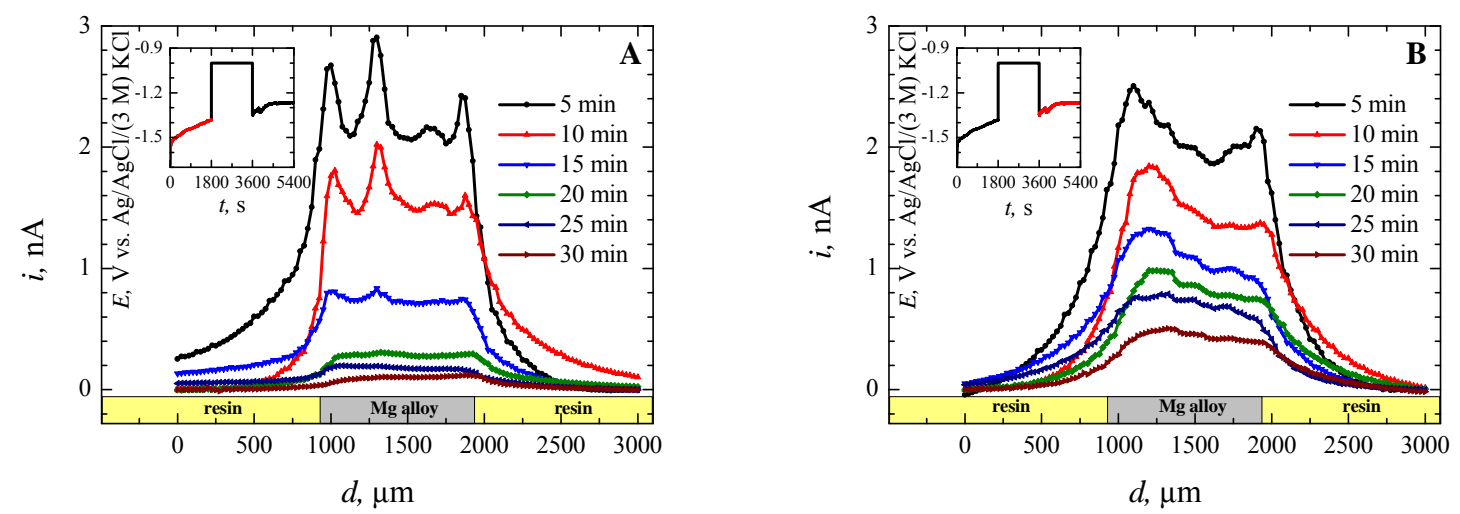

Figure 1. Amperometric SECM line scans recorded with a Pt microelectrode $\left(E_{\text {tip }}=-0.05 \mathrm{~V}\right.$ vs. $\mathrm{Ag} / \mathrm{AgCl} /(3 \mathrm{M}) \mathrm{KCl})$ travelling above an $\mathrm{AZ63}$ sample immersed in $1 \mathrm{mM} \mathrm{NaCl}$ solution. The line scans were monitored along the same pathway for different times before (A) and after (B) application of an anodic polarization (30 min at $E_{\text {sample }}=-1.0 \mathrm{~V}$ vs. $\mathrm{Ag} / \mathrm{AgCl} /(3 \mathrm{M})$ $\mathrm{KCl}$ ). No polarization was applied to the AZ63 sample during SECM operation. The inset shows the potential program applied to the AZ63 sample: $30 \mathrm{~min}$ at OCP, $30 \mathrm{~min}$ at $E_{\text {sample }}=$ $-1.0 \mathrm{~V}$ vs. $\mathrm{Ag} / \mathrm{AgCl} /(3 \mathrm{M}) \mathrm{KCl}$, and $30 \mathrm{~min}$ at the OCP. The red sections of the E-t plot indicate the stage of the potential program where the line scans were recorded. The curves were acquired using a $25 \mu \mathrm{m}$ diameter Pt ME with an $R G<10$; tip-sample distance: $20 \mu \mathrm{m}$; scan rate: $25 \mu \mathrm{m} \mathrm{s}^{-1}$.

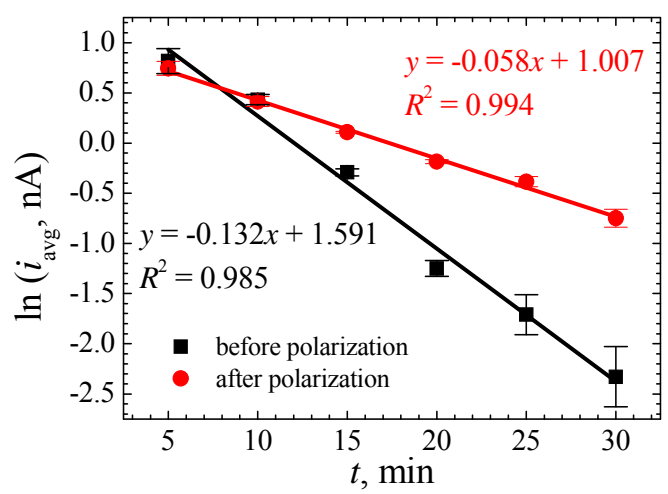

Figure 2. Time evolution of the average $\mathrm{H}_{2}$ fluxes in the line scans of Figure 1 that were recorded from an AZ63 alloy immersed in $1 \mathrm{mM} \mathrm{NaCl}$ solution before (A) and after (B) application of an anodic polarization $\left(30 \mathrm{~min}\right.$ at $E_{\text {sample }}=-1.0 \mathrm{~V}$ vs. $\mathrm{Ag} / \mathrm{AgCl} /(3 \mathrm{M}) \mathrm{KCl}$ ). 



Figure 3. Optical micrographs of an AZ63 magnesium sample immersed in $1 \mathrm{mM} \mathrm{NaCl}$ : A) prior to the addition of the test solution; B) at the spontaneous OCP in the test solution; C) following the application of an anodic polarization at $-1.00 \mathrm{~V}$ vs. $\mathrm{Ag} / \mathrm{AgCl} /(3 \mathrm{M}) \mathrm{KCl}$ for 10 $\min$.
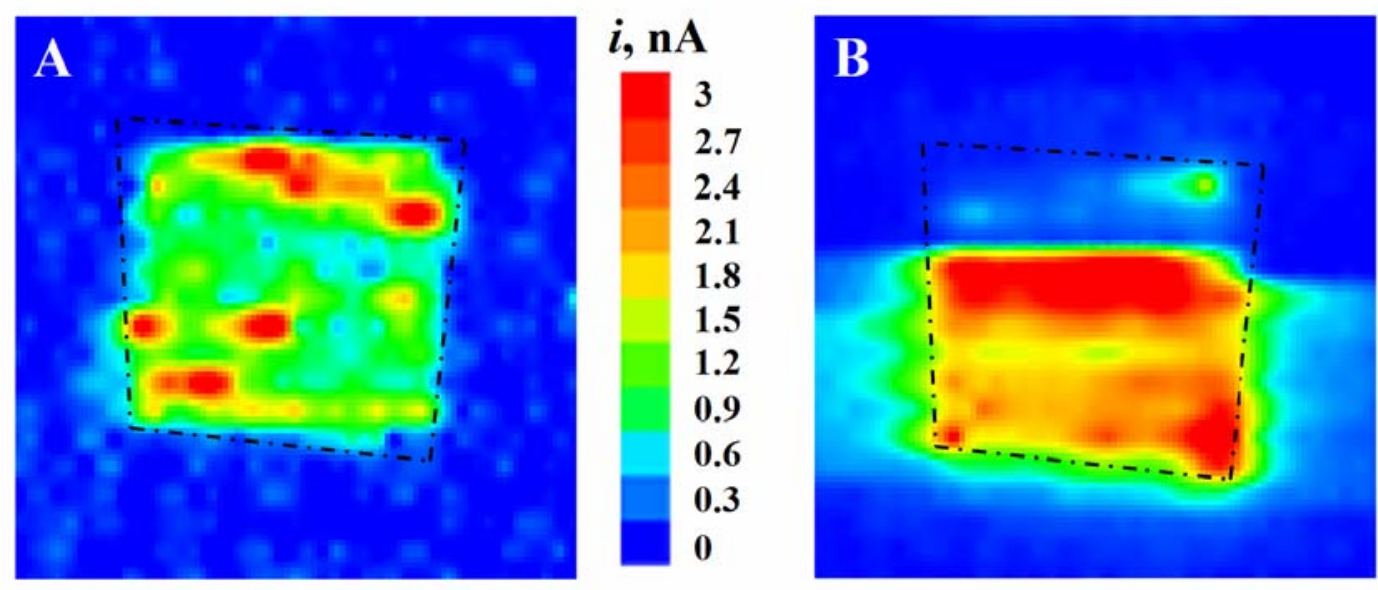

Figure 4. Amperometric SECM map scans recorded with a Pt microelectrode $\left(E_{\text {tip }}=-0.05 \mathrm{~V}\right.$ vs. $\mathrm{Ag} / \mathrm{AgCl} /(3 \mathrm{M}) \mathrm{KCl})$ travelling above AZ63 samples immersed in: (A) $3 \mathrm{mM} \mathrm{NaCl}$, (B) 1 $\mathrm{mM} \mathrm{NaCl}+1 \mathrm{mM} \mathrm{MgCl}_{2}$. Images represent an area of $2000 \mu \mathrm{m} \times 2000 \mu \mathrm{m}$. Samples were left unbiased at their corresponding OCP. They were acquired using a $25 \mu \mathrm{m}$ diameter Pt ME with an $R G<10$; tip-sample distance: $20 \mu \mathrm{m}$; scan rate: $16.7 \mu \mathrm{m} \mathrm{s}^{-1}$. 



Figure 5. Potentiometric SECM map scans recorded with a $\mathrm{Sb} / \mathrm{Sb}_{2} \mathrm{O}_{3}$ microelectrode travelling above AZ63 samples immersed in: (A) $3 \mathrm{mM} \mathrm{NaCl}$, (B) $1 \mathrm{mM} \mathrm{NaCl}+1 \mathrm{mM}$ $\mathrm{MgCl}_{2}$. Images represent an area of $2000 \mu \mathrm{m} \times 2000 \mu \mathrm{m}$. Samples were left unbiased at their corresponding OCP. Tip-sample distance: $20 \mu \mathrm{m}$; scan rate: $16.7 \mu \mathrm{m} \mathrm{s}^{-1}$.
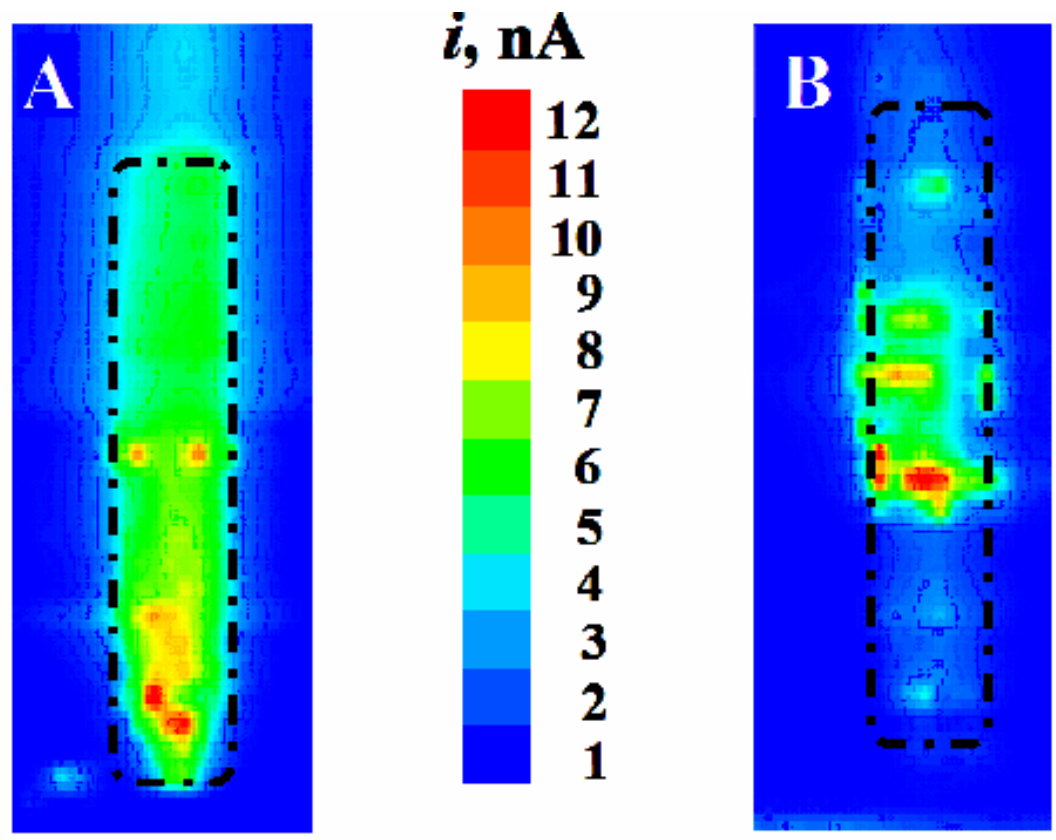

Figure 6. Amperometric SECM map scans recorded with a Pt microelectrode $\left(E_{\text {tip }}=-0.05 \mathrm{~V}\right.$ vs. $\mathrm{Ag} / \mathrm{AgCl} /(3 \mathrm{M}) \mathrm{KCl})$ travelling above $\mathrm{AZ63}$ samples immersed for $60 \mathrm{~min}$ in: (A) $0.2 \mathrm{M}$ $\mathrm{NaCl}$, and (B) $0.1 \mathrm{M} \mathrm{MgCl}_{2}$. Images represent an area of $1000 \mu \mathrm{m} \times 3000 \mu \mathrm{m}$. Samples were left unbiased at their corresponding OCP. They were acquired using a $25 \mu \mathrm{m}$ diameter Pt ME with an $R G<10$; tip-sample distance: $20 \mu \mathrm{m}$; scan rate: $16.7 \mu \mathrm{m} \mathrm{s}^{-1}$. 



Figure 7. Amperometric SECM map scans recorded with a Pt microelectrode $\left(E_{\text {tip }}=-0.05 \mathrm{~V}\right.$ vs. $\mathrm{Ag} / \mathrm{AgCl} /(3 \mathrm{M}) \mathrm{KCl})$ travelling above $\mathrm{AZ63}$ samples immersed in: (A) $1 \mathrm{mM} \mathrm{NaCl}+10$ mM EDTA, (B) $1 \mathrm{mM} \mathrm{NaCl}$. Samples were left unbiased at their corresponding OCP. Images represent an area of $2000 \mu \mathrm{m} \times 2000 \mu \mathrm{m}$. They were acquired using a $25 \mu \mathrm{m}$ diameter Pt ME with an $R G<10$; tip-sample distance: $20 \mu \mathrm{m}$; scan rate: $16.7 \mu \mathrm{m} \mathrm{s}^{-1}$.


Figure 8. Amperometric SECM map scans recorded with a Pt microelectrode $\left(E_{\text {tip }}=-0.05 \mathrm{~V}\right.$ vs. $\mathrm{Ag} / \mathrm{AgCl} /(3 \mathrm{M}) \mathrm{KCl}$ ) travelling above $\mathrm{AZ63}$ samples immersed in: (A) $1 \mathrm{mM} \mathrm{NaCl}+10$ mM EDTA, (B) $1 \mathrm{mM} \mathrm{NaCl}$. Samples were polarized at $-1.0 \mathrm{~V}$ vs. $\mathrm{Ag} / \mathrm{AgCl} /(3 \mathrm{M}) \mathrm{KCl}$. Images represent an area of $2000 \mu \mathrm{m} \times 2000 \mu \mathrm{m}$. They were acquired using a $25 \mu \mathrm{m}$ diameter Pt ME with an $R G<10$; tip-sample distance: $20 \mu \mathrm{m}$; scan rate: $16.7 \mu \mathrm{m} \mathrm{s}^{-1}$. 

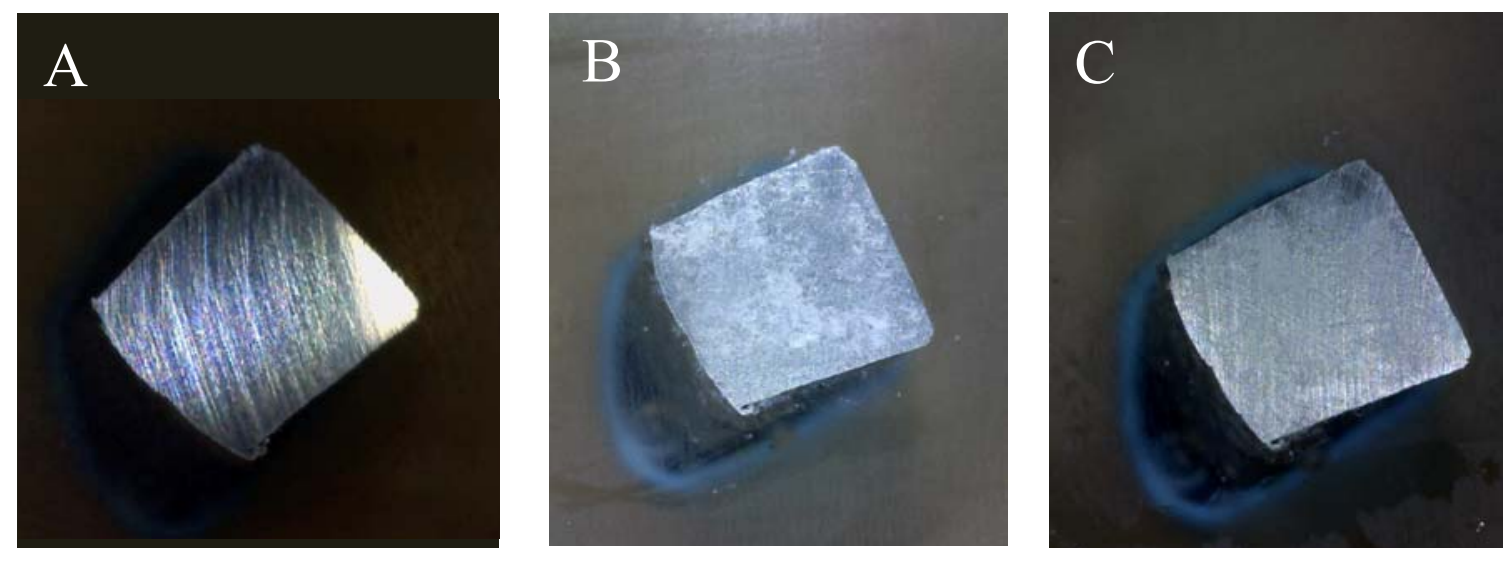

Figure 9. Optical micrographs of a nickel sample: (A) prior, and (B) after deposition of a $\mathrm{Mg}(\mathrm{OH})_{2}$ layer from a $\mathrm{MgCl}_{2} / \mathrm{Mg}\left(\mathrm{NO}_{3}\right)_{2}$ containing solution as described in Ref. [57]; (C) after the $\mathrm{Mg}(\mathrm{OH})_{2}$ coated nickel sample was exposed to $0.01 \mathrm{M}$ EDTA solution for $5 \mathrm{~min}$.

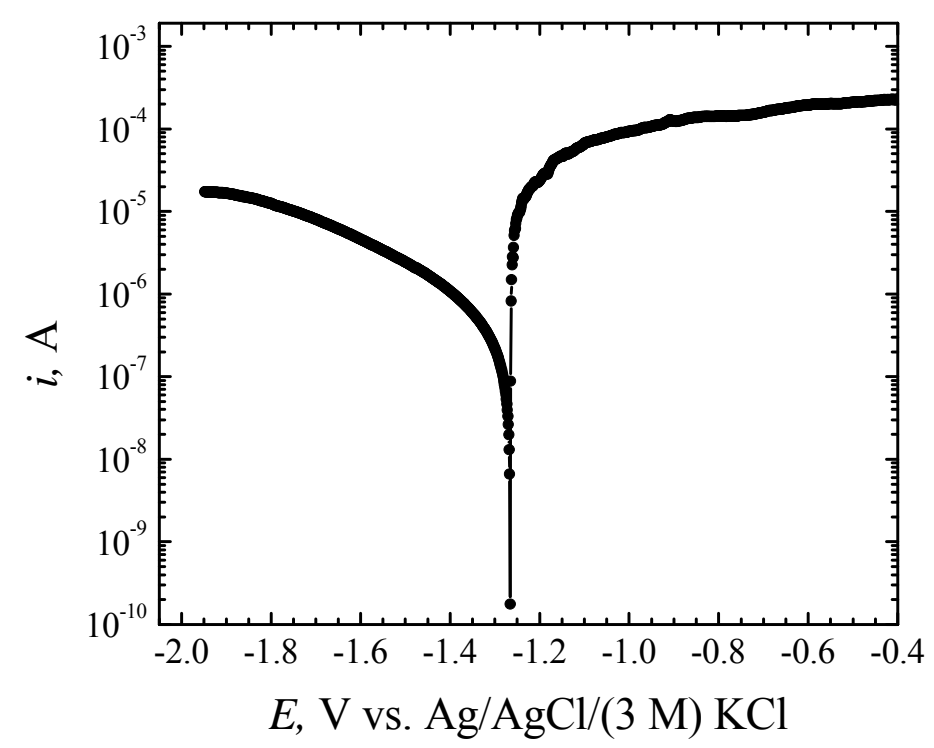

Figure 10. Typical Tafel plot of an AZ63 sample immersed in $1 \mathrm{mM} \mathrm{NaCl}$. Experiment performed in a single scan upwards starting from the cathode region at scan rate of $5 \mathrm{mV} \mathrm{s}^{-1}$. 

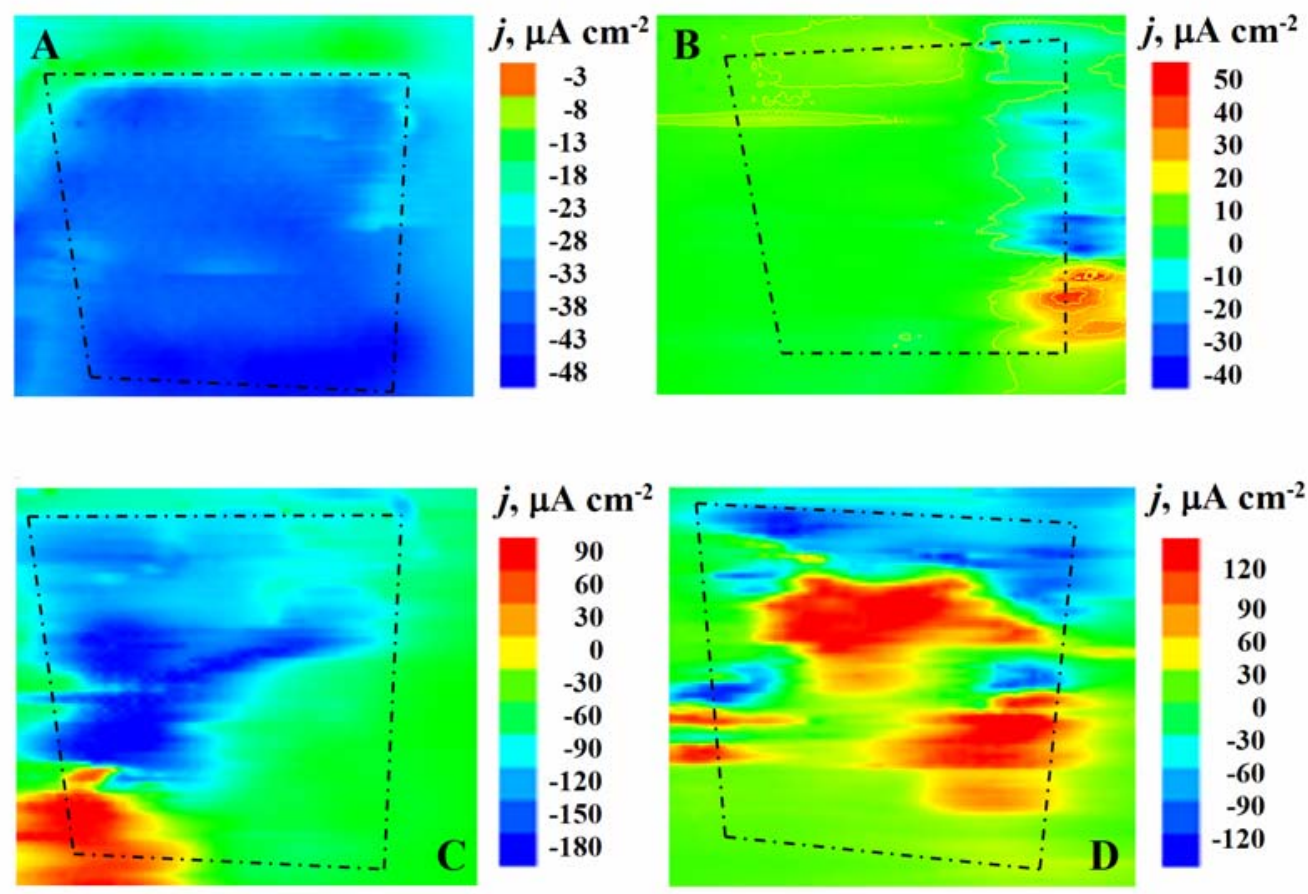

Figure 11. SVET map scans recorded above an AZ63 sample immersed in $1 \mathrm{mM} \mathrm{NaCl}$ subjected to different polarization conditions: (A) cathodically polarized at $-1.7 \mathrm{~V}$ vs. $\mathrm{Ag} / \mathrm{AgCl} /(3 \mathrm{M}) \mathrm{KCl}$; (B) spontaneously corroding at its OCP; anodically polarized at (C) -1.3 and (D) $-1.0 \mathrm{~V}$ vs. $\mathrm{Ag} / \mathrm{AgCl} /(3 \mathrm{M}) \mathrm{KCl}$. Images represent an area of $1500 \mu \mathrm{m} \times 1250 \mu \mathrm{m}$. The average height of the vibrating tip was $50 \mu \mathrm{m}$; vibration amplitude along $Z$ axis: $20 \mu \mathrm{m}$; step width: $18 \mu \mathrm{m}$. 